\title{
A Systemic Perspective on Racism in Football: The Experience of the BRISWA Project
}

\author{
STEFANO ARMENIA ${ }^{1}$ \\ s.armenia@unilink.it \\ Link Campus University \\ CAMILLO CARLINI \\ c.carlini@unilink.it \\ System Dynamics Italian Chapter
}

JASON PAPATHANASIOU

jasonp@uom.edu.gr

University of Macedonia

\section{ALESSANDRO POMPEI}

ales.pompei@gmail.com

System Dynamics Italian Chapter

GEORGIOS TSAPLES

gtsaples@uom.edu.gr

University of Macedonia

\begin{abstract}
The objective of this paper is to present the process for the development of a causal loop diagram that captures the relevant aspects of racism in football, through a holistic, top-down approach. To do so, a series of workshops/sessions has been organised with experts in the field and with the purpose of designing a tool that could be used to get better insights into how racism in football emerges and where are the potential areas where policymakers could use as leverage for effective counter-measures. The diagram demonstrated the multi-faceted nature of racism, the phenomena that might give rise to it and the elements that could serve as leverage in potential counter-measures. Some of the most interesting results include the following: the power structures of society and football should adapt to represent the actual demographic make-up of each country. Furthermore, policymakers should involve media
\end{abstract}

\footnotetext{
${ }^{1}$ Corresponding author.
} 
more directly in every attempt to fight racism. Finally, racism in football is a mirror of racism in society. Hence, any attempt to combat racism in football should be interlinked with corresponding efforts to fight discrimination in society.

\section{Introduction}

The 2011-2012 season of the English Premier League was stigmatised by two events that at the time seemed to come out of the blue. In a game between Manchester United and Liverpool FC, Luiz Suarez, a Liverpool forward, and Patrice Evra, a Manchester United defender, were seen to be involved into a verbal banter, not different than any that occurs at any football game around the world. However, after the end of the game, Patrice Evra complained to his manager that Suarez had abused him racially. The management of Manchester United brought the incident to the attention of the English Football Association (FA) and the incident received widespread media attention.

The second incident that received even more attention and divided the British football community, involved the Chelsea FC captain John Terry and Anton Ferdinand - player of Queens Park Rangers. The latter accused Terry of racial abuse. The case proved to be a media sensation mainly because John Terry was also the captain of the national team at the time. The Regulatory Commission of FA fined Terry for $£ 220,000$, banned him from playing for four games and the player issued a very public apology (The Daily Telegraph, 2012).

The reason why those incidents received such wide attention goes deeper than just the status of the football players. For many fans, citizens and policymakers these two incidents indicated that maybe the anti-racism campaigns that dominated English Football in the 1990s (e.g., Kick It $\mathrm{Out}$ ) were not as successful as they were perceived to be. More importantly, these two incidents ignited a fear that maybe English football had returned (or was in the verge of returning) to its 'bad' decades of the 1970s and 1980s.

Racism in football is not a new phenomenon. There have been periods where it seemed to have vanished, through efforts to prohibit racist behaviour from and amongst the fans and governmental attempts to prevent racism through legislation. However, evidence suggests it remained.

Racism emerged in the 1970s as a major problem for the sport and has persisted ever since (Cashmore and Cleland, 2014) at all its level. Furthermore, it takes an appallingly wide range of forms, and it is a problem for all European countries (Kassimeris, 2009). Finally, it remains deeply rooted and pervasive in contemporary amateur football in countryside villages and semi-rural areas (Long et al., 2000), which possess almost exclusively white populations (Burdsey, 2006; Burdsey, 2007).

Recognising that the fight against racism in football is continuous and that there is a need to re-evaluate how the phenomenon is studied, viewed and approached, led to the development of the BRISWA (The Ball Rolls in the Same Way for All) project. The project is co-funded by the Erasmus+ Programme, and it involves 7 private and public organisations in 6 different countries and its objectives include: (a) studying the current perceptions of people with regards to racism in football; (b) applying the discipline of Systems Thinking with the purpose of understanding the structure of the system that generates racism; and (c) initiating an antiracism campaign specifically focused on football academies in the partner countries. 
The objective of the current paper is to analyse how the phenomenon of racism in football emerges as part of the socio-economic environment and determine which areas could act as catalysts in designing and implementing successful counter-measures.

The objective results from applying Systems Thinking, as was used in the context of the BRISWA project, in studying the phenomenon of racism in football. The rest of the paper is organised as follows: Section 2 presents the theory of racism in football and, more specifically, how it has been defined through the decades and the reasons that racism in football has persisted. The focus of the ensuing sections is the results from the application of Systems Thinking, while conclusions and future avenues of research are discussed in the final section of the paper.

\section{What is racism}

In this section, the focus is trying to provide definitions on what racism is, how it has affected football and what its evolution has been through the decades.

The first issue to consider is who the victims of racist behaviour are. In that regard, the term BAME (Black, Asian and Minority Ethnic people) can be considered a marker that refers to non-white communities, indigenous to the various countries. This marker has been widely used in public policy and public dialogue (Long et al., 2009), despite the fact that defining what racism actually is, proves to be a more complex situation.

According to FIFA (FIFA, 2006), racism is based on skin colour as an outward indication of ethnic origin. Similarly, Macpherson (1999) defines racism as the behaviour (the words or the actions) that either provide benefits or disadvantages to groups of people based on the colour of their skin, their culture or ethnic origin. However, what Macpherson (1999) points out is that racism can be expressed both overtly and covertly, and both types are equally damaging.

According to Long et al. (2000), racism arises from the conceptual construct that people can be divided into different genetic categories. This biological categorisation is used to justify actions that promote and sustain inequality. Llopis-Goig (2013), however, enriches the definition by indicating that biological inheritance cannot be the sole factor, but cultural differences should also be considered when racism is studied.

Solomos and Back (1996) conducted a study on racism in society and described it as a mutable and changing phenomenon and attributed it to notions of biological (or pseudo-biological) and cultural differences that are utilised with the purpose of legitimising hierarchies of racial dominance and discrimination. Moreover, this aspect can be expressed without the conscious knowledge of the instigator, a term referred to as subconscious or indirect racism (Long et al., 2000). This subconscious or indirect form of racism might stem from frustration, insecurity, lack of knowledge and, in many cases, lack of understanding. It can derive from the existence of a perception that the massive arrival of immigrants (or the 'others') will endanger the indigenous/national identity (Llopis-Goig, 2013).

Even though most definitions (and research) have focused on the aspect of human behaviour, recent endeavours have identified and defined racism at a different level. This form has been termed as 'institutional racism' (Macpherson, 1999: 49): 
The collective failure of an organization to provide an appropriate and professional service to people because of their colour, culture or ethnic origin. It can be seen or detected in processes, attitudes and behavior which amount to discrimination through unwitting prejudice, ignorance, thoughtlessness and racist stereotyping which disadvantage minority ethnic people.

In more detail, institutional racism can be considered as a phenomenon mainly rooted in the structure of society. Garland and Rowe (1999) further suggest that this form of racism can actually be even more harmful to individuals. Garland and Rowe (2001: 335) also note that initiatives would benefit from having more sociological thinking behind them: "Adopting these perspectives at the local level would help both clubs and fans to develop and sustain more meaningful programs that suit the prevailing conditions".

As a result, it can be observed that racism is a multi-faceted, complex issue, and there is no single definition that can fully capture it. As with its inherent nature, its definitions have evolved over the years to include (apart from biological aspects) culture and societal structures. Furthermore, it can be expressed in different forms - covert or overt - all of which can be equally dangerous and harmful.

\section{Racism in football}

Figure 3.1 illustrates a timeline of major events in football (and society) that have influenced how racism is expressed and addressed in football.

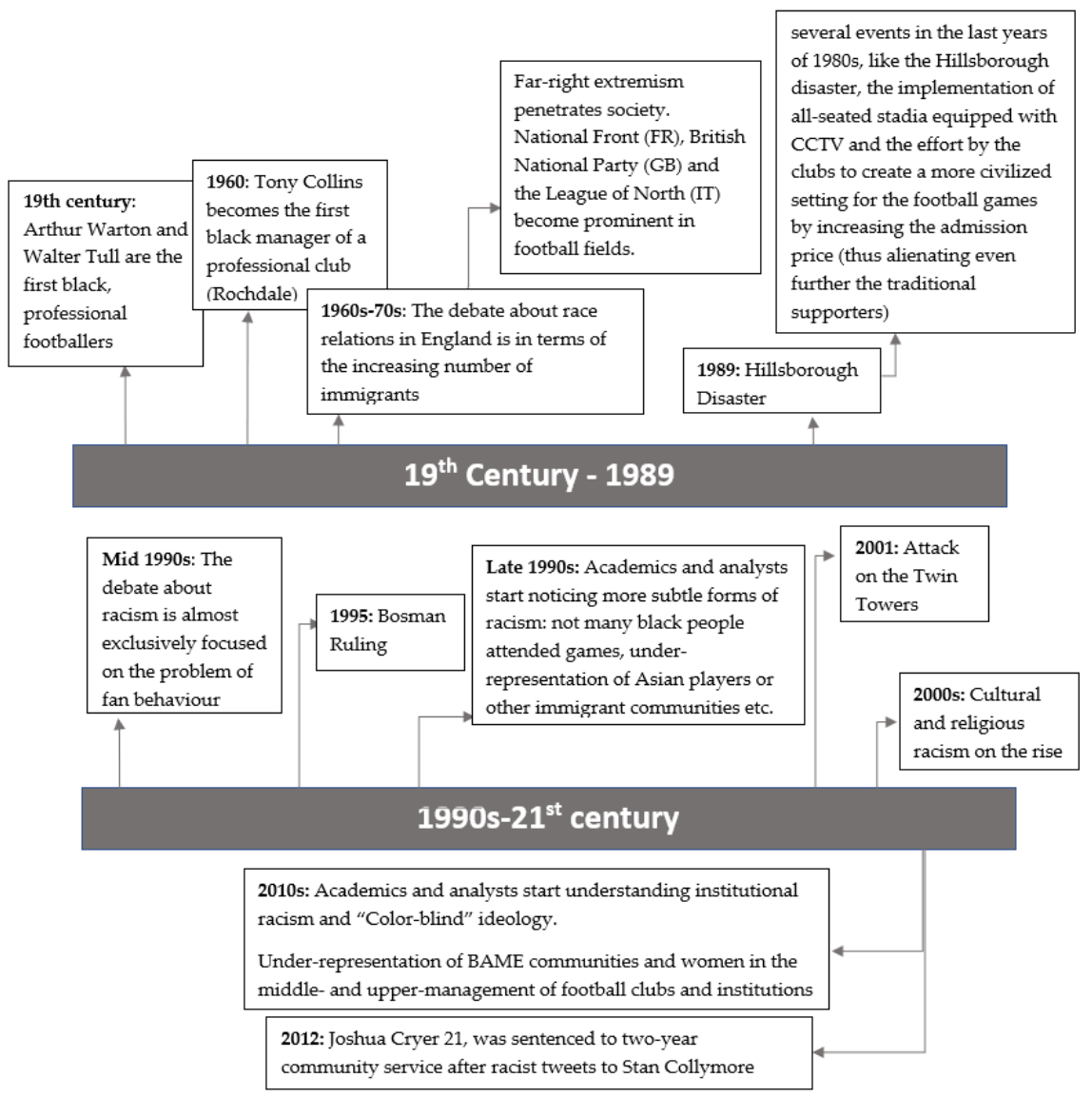

Figure 3.1. Timeline of the evolution of racism in football. 
As can be observed from this timeline, racism in football has been viewed under different perceptions over the years. In its early stages, it was considered merely as a problem of supporters' and players' behaviour, who did not accept players that did not share their colour skin. However, the Bosman ruling shifted this discrimination towards players of other teams. It is only natural that the major anti-racist campaigns sought to combat this type of behaviour.

Consequently, the attack on the Twin Towers put forwards culture and religion as the focal points of racism in football. It was not different from racism about skin colour; only, the focus of attack changed. As a result, anti-racism campaigns expanded their focus to include not only skin colour but also cultural identity. It is only in the last years that researchers and scholars have started noticing racism in the structure of the system itself, that is, institutional racism.

Furthermore, the penetration of social media in society is daily, forcing policy- and decisionmakers to acknowledge that this might be another area where they will have to devote resources in order to fight racism. Nonetheless, the conclusions of researchers and academics about the latest manifestations of racism have not yet been extensively used in the message of anti-racism campaigns or in the directives of the governing bodies of football.

\section{Why has racism persisted in football?}

There are a number of reasons that can explain why racism has persisted in football despite the efforts done to fight it. Firstly, the perception that racist incidents are still considered unusual, episodic and spontaneous, originating from supporters' (or players') inherent biases, still dominates football culture (Müller, Van Zoonen and De Roode, 2007; Burdsey, 2014). Furthermore, there is an effort to diminish the significance of a racist attack as merely a joke with no harm intended (Long, 2000). As a result, racism in football persists because it is still viewed as an individual, private matter.

This colour-blind ideology dominates football and, as a result, football authorities refuse to acknowledge that past initiatives have not tackled the underlying causes (Burdsey, 2007). Essentially, it is not that race is ignored; rather, there is the tendency to dismiss it at as not responsible for hierarchy and structural discrimination (Burdsey, 2014; Renfrew and Snyder, 2016).

The particular blindness in combination with the historical legacy of racism has contributed to the relative under-representation of ethnic minorities not only to the management structures but also to the ones attending the games themselves (Pinto, Drew and Minhas, 1997; Bains and Johal, 1998), especially in countries where the demographic profile of the national population is perceived to be homogeneous (Long et al., 2009; Bradbury, 2013; Krasnoff, 2017).

Moreover, racism has persisted in football due to extreme visibility. High media profile enjoyed by football clubs and players may have emboldened their fans into believing that racist behaviour is something that has no real consequences. Furthermore, the achievements of minority football players enhance the perception that football is more inclusive than other spheres of social life (Bradbury, 2013), further encouraging the belief that racism in football is sporadic and an individual issue.

Finally, King (2004) states that racism in football is nothing more than a mirror of racism in society. Especially in Europe, where there is a wider discussion on issues of national identity, 
citizenship and a problem of increased migration flows. In combination with a falling birth rate across Europe, migrants are necessary, but their social presence is considered undesirable (Doidge, 2015), thus perpetuating the stereotype of minority ethnic people being associated with danger and criminality (Talbot and Bose, 2007).

In conclusion, there is a need to look at the problem of racism in a more comprehensive way and treat it as a systemic problem. Sporadic attempts to address only specific aspects of it have merely driven racism underground, taking forms that are harder to detect.

\section{A Systems Thinking approach to racism}

As is evident from the previous sections, the issue of racism is a complex one, since it consists of different facets, different elements that can give rise to it and different people perceiving it in different ways. Furthermore, being an abstract issue, it cannot be easily quantified. Moreover, from a decision-making point of view, it has to be assessed constantly: it requires more than one decision, which are interdependent and the environment in which racism is manifested changes over time. As a result, the methodology that should be used in order to study racism in football and its consequences must offer the possibility to represent complex relationships in a complex environment.

Systems Thinking and its operational form, System Dynamics, is a way of looking at systems from a holistic point of view. Its purpose is to determine what is the system's structure and in what way the structure affects its behaviour over time (Sterman, 2000). As a result, the main objective is to understand the mechanics behind the emergence of that behaviour and determine the consequences that potential policies could have (either desired or undesired; see Armenia, Tsaples and Carlini, 2018; Myrovali et al., 2018).

The method can be used in purely qualitative, purely quantitative or any combination of the two models. Its main elements are feedback loops, non-linearities, time delays and internal structures which are considered the causes of the generated dynamics in the system under study (Meadows, 1980). The identification of the most important variables of a system and how they are causally connected form the Causal Loop Diagram (CLD). Despite its qualitative nature, the CLD is considered an important tool since it allows to clarify the mental models of the system, it maps its main elements and their inter-connections and acts as a communication tool, with which difficult notions can be disseminated to non-experts.

In the context of the BRISWA project, the CLD was developed in a series of Group Model Building Sessions, where experts in the area gathered together and under the guidance of the BRISWA team, shared their expertise on the particular field of study, shared information and advanced a CLD to represent the phenomenon of racism in football.

\section{Group Model Building Activities}

The first activity was to find the relevant experts to the issue. The main characteristic of whom is that their research is focused on racism and discrimination with an emphasis on sports. Consequently, the development of the Causal Loop Diagram was not based on the traditional technique of deriving information from the literature. Experts in the field were gathered 
together and through debate, a common representation of the socio-economic system in which racism can appear was developed.

The identification of such a group of experts was driven by the literature review on the issue (part of which was presented in the previous section). Among the many publications that were studied, an initial group of authors was gathered, and they were subsequently contacted. The process led to the selection and engagement of 7 experts:

- Daniel Burdsey, Reader and Deputy Head of School (Research and Enterprise) in the School of Sport and Service Management at the University of Brighton (UK);

- $\quad$ Ellis Cashmore, Visiting Professor of Sociology at Aston University (UK);

- $\quad$ Aldo Grauso, Professor of Sport Psychology at Università Niccolò Cusano (IT);

- Christos Kassimeris, Heads the School of Humanities and Social Sciences at European University Cyprus;

- $\quad$ Piara Powar, Head of Strategy and Global Operations at FARE Network (Fight Against Racism in Europe);

- Alberto Testa, Applied Sociologist (sociological social psychology) of Deviance and Crime, and Senior Lecturer in Criminology at University of West London (UK);

- Jacco van Sterkenburg, Assistant Professor in the Department of Media and Communication and the Erasmus Research Centre for Media Communication and Culture (ERMeCC), Erasmus University Rotterdam (NL).

Consequently, a series of workshops was organised in various cities in the partner countries, where the experts were introduced to the details of the project, the discipline of Systems Thinking and what their role would be in the development of the CLD. In more detail, the experts were asked to reflect on questions such as "how would you measure the 'intensity' of the presence of racism in a certain context?", "which are the input factors that affect positively and negatively the actual intensity degree of racism in football?". The aim of these questions was to determine the central questions of the study; mainly how the presence of the racism in football could be measured, giving a degree of intensity and if they saw any systemic relation of causality.

With the help of the coordinators of the workshops, the answers were translated into codified variables and the next step was to determine which and of which type the causal relations are among them. The final product of these sessions was the production of a detailed Causal Loop Diagram. In addition, it allowed people to think in a different way than usual and examine different perspectives when facing such a complex issue. Finally, the produced CLD can serve as an instrument of communication to policymakers on the complexity of racism and what policies could or could not potentially succeed.

\section{The Causal Loop Diagram}

The following paragraphs illustrate the final product of the Group Model Sessions along with the explanations and the main conclusions. 


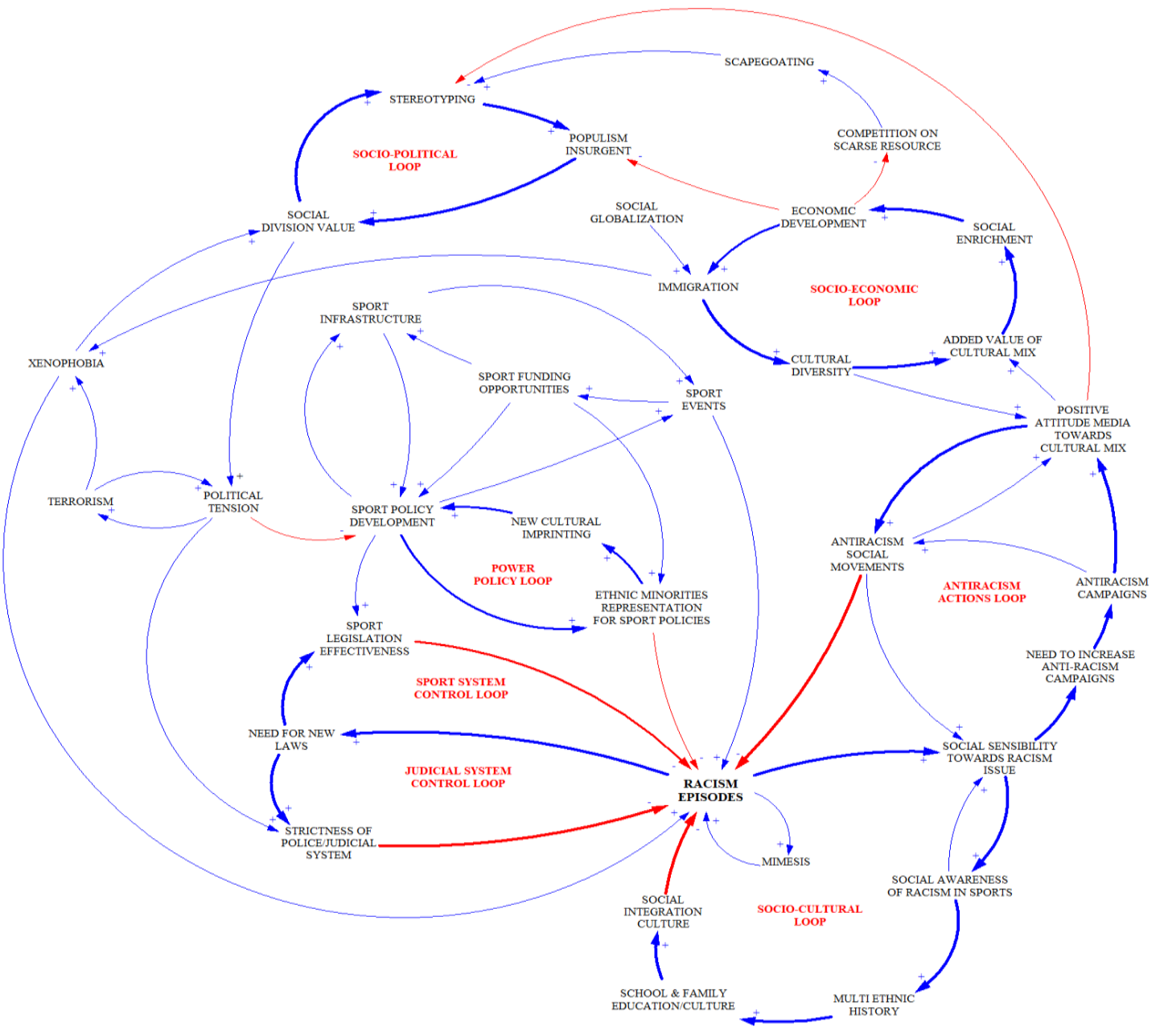

Figure 7.1. The CLD of racism in football.

The starting point of the model is represented by the racism episodes, which serve as its core. This variable was indeed identified by experts as one of those that can provide reliable information about the level of racism inside football stadia analysing its trends and changes. The choice of this variable is due to the fact that racist episodes can be quantified, exploring specific databases that deal with such topics. Being allowed to quantify the core variable of the model is critical for two reasons: on the one hand, the quantification helps to better understand the real meaning of the variable and prevents possible biases between different people and their perceptions. On the other hand, as the next step of a CLD is the creation of a Stock and Flow diagram (S\&F), choosing a quantitative variable as the core variable facilitates the development of the $S \& F$, making the process more coherent and linear.

In the CLD displayed in Figure 7.1, an effort was made in order to include as many relevant themes regarding racism and its system as possible in order to give a wide overview of all processes and behaviours that are present in this complex system.

By analysing the final model, developed by the joint action of modellers and experts, some insightful loops were identified. They could be divided into three main categories:

1. Socio-political-economic loops;

2. Institutional loops; 
3. Socio-cultural and antiracism loops.

It should be stated that the loops to be described do not act in isolation but are interconnected with each other and isolated variables.

For the Socio-political-economic sub-system, there are two reinforcing feedback loops (positive feedbacks portray social, political and cultural self-reinforcing processes) that may generate vicious or virtuous circles at the societal level.

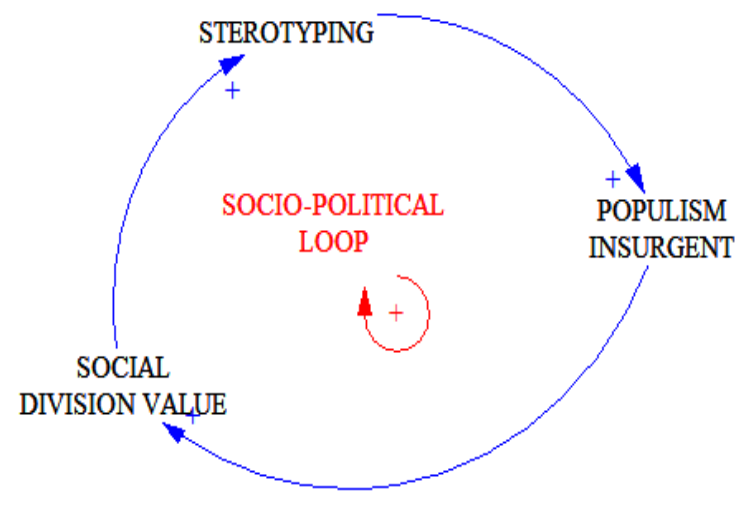

Figure 7.2. Socio-Political Loop.

The first loop (Figure 7.2) considers three variables: Populism insurgent, Social division value and Stereotyping. The result of the relationships between these variables is a reinforcing feedback loop. In fact, when the socio-economic climate experiences problems, populism could occur and create some new trends of opinion, that generate social division value. Stereotyping is one of the manifestations of social division; in fact, in this situation, people are prone to judge and group the 'others' in mental clusters, defining their lifestyle or even their intentions on the basis of the cluster they belong to. This way of thinking hugely feeds the populism insurgent variable and, consequently, the entire feedback loop.

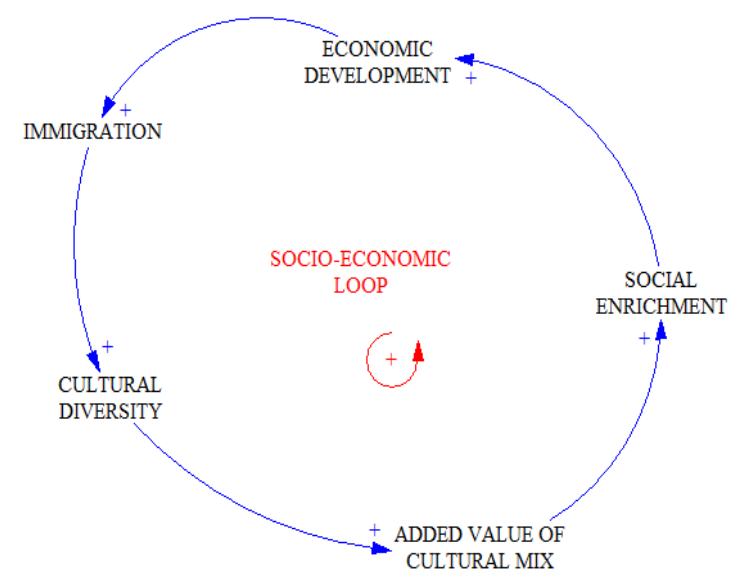

Figure 7.3. The Socio-Economic Loop. 
The second loop (Figure 7.3), which is connected to the first as they influence each other, considers the impact of the economic climate on socio-cultural diversity and enrichment. If the economic climate of a country rises, there is an increase in migratory phenomena in general, due to the fact that the country is going to have greater resources and opportunities for people who wish to find new possibilities. This event triggers a virtuous circle which increases cultural diversity and social enrichment over time, with benefits for economic development due to cultural confrontation that brings new knowledge and new capacities.

The institutional loops regard powers structures inside football and control governance authorities. There are three important loops who belong to this group.

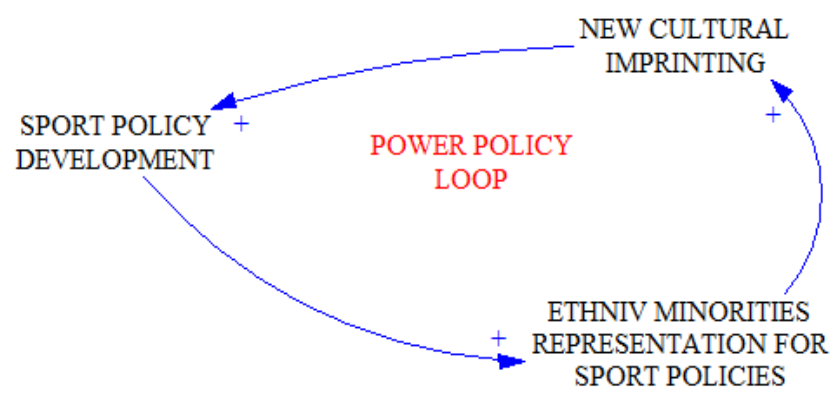

Figure 7.4. The Power Policy Loop.

The Power policy loop (Figure 7.4) is a reinforcing one that highlights the system of power structures. Specifically, what emerged in the brainstorming with the experts is that sports organisations often reflect the same power structure that dominates society. Power structures influence the development of sport policies that, in turn, affect the political structure of sports organisations in the direction of reproducing, at least partially, those power structures. Therefore, the representation of minorities in the upper hierarchical layers of sports organisations mirrors the societal distribution of power and representation. Consequently, in a society, if ethnical minorities are excluded from political participation, it can be expected that the same bias applies to sport organisations, as representative portions of the same society. It can be suggested that the feedback loop urges to reflect on the effective distribution of representation in different societies. 


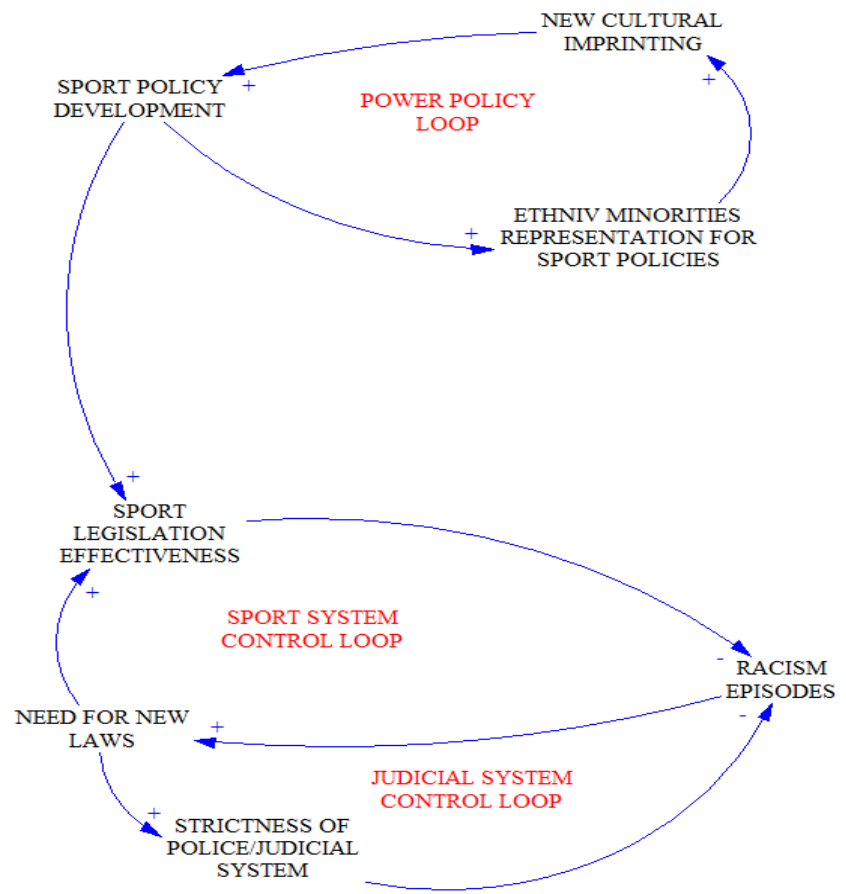

Figure 7.5. Sport system control and judicial system loops and their direct connection with the power policy loop.

Beside positive feedback loops, the model elicits two negative feedback loops that capture two key governance mechanisms (Figure 7.5). The mechanisms reflect, respectively, on judicial/police systems (Judicial System Control Feedback) and sport legislation (Sport System Control Feedback). Both mechanisms are typical homeostatic-control mechanisms. As racist episodes occur, the need for intervention intensifies, thereby triggering actions from either judicial/police system or sports legislation. These two governance mechanisms are at the core of the modelling exercise. Any further attempt of modelling policies may find useful to begin the effort by further articulating the description of these negative feedbacks.

It is worth mentioning that, in the modelling meeting, the drawing of the two negative feedbacks evoked two issues that may inform further modelling. First, the design of policymaking should cope with the following questions: to what extent do the two negative feedbacks collaborate or are in competition? In this light, the experts suggested that, often, in the application of sports legislation, sports organisations tend to raise curtains that protect the sport system. An issue that emerges, therefore, is the way in which sports legislation and judicial/police systems should be integrated and/or coordinated. Second, the portrayal of the negative feedback loops speaks to the need for investigating the length of delay that characterises the reaction of both sports legislation or judicial/police systems. In this respect, in different countries, the delay needed for racist episodes to produce a modification in legislation may differ greatly. However, given the work of the positive feedback loop generated by the Mimesis - which refers to the key role of imitation in encouraging or discouraging racist behaviour -, delays in responding to racist episodes may allow the insurgence of vicious mimetic behaviour. On the other hand, the rapidity of the intervention to discourage racism at the very inception of racist episodes is likely to curb the mentioned positive loop. From this perspective, the modelling session highlighted the connection between the two negative feedback loops (Sport System Control Feedback and Judicial System 
Control Feedback) and the positive feedback loop as a key point of attention and intervention in the model.

The Socio-cultural loop is a balancing one that illustrates the beneficial effects that the historical familiarity of a country with the phenomenon of multi-ethnicity brings about. Hence, if educational systems are informed by the acknowledgement that multi-ethnicity is a physiological trait of the society, rather than a pathological deviation from the norm, younger people are soon socialised to recognise and accept difference. In other words, education systems that crystallise multi-ethnicity reinforce the preservation of a physiological level of multi-ethnicity at the societal level by increasing the sensibility and awareness level towards racist episodes.

The Antiracism actions loop is of particular interest to policymakers, whose objective is to mitigate racism and discrimination. Generally, when racist episodes occur, there is a wide rise of sensibility toward the theme; this generates the need to increase the actual anti-racism campaigns because probably they are not doing enough. The campaigns have a beneficial effect on anti-racism social movements, which are one of the most important enforcement actions against racism, but this effect could be even stronger if media enter in the process, by providing their contribution in defending the cultural mix.

In this respect, the balancing feedback loop that arises from this analysis invites, for example, to reflect on the role of media in communicating racist behaviour, because media are able to move people and trigger bandwagon effects useful for strengthening messages and ideas of equality.

\section{Practical implications}

In conclusion, the Causal Loop Diagram revealed a series of interesting results that not only highlight how racism can occur and persist in football stadia but also illustrates what the potential areas are where the success of a policy could increase. As a result, the Power Policy Loop highlights that the fight against racism in football should start with the management of the clubs. Should they diversify their upper echelon to accurately represent society, it would signal that multi-cultural behaviours are the norm.

The socio-economic loops indicated that no campaign against racism should be limited inside the field. If the organisers wish to increase the probability of success, they should recognise that racism in sports is not different from racism in society. Only by tackling them both could the anti-racism campaigns be successful.

Finally, the negative feedback loops highlighted the need for a common framework of laws and rules that apply to everyone, regardless of their (socio-economic standing). A policy framework that fortifies and secures fair play while respecting cultural identity could lead to less racist phenomena.

\section{Conclusions}

Racism in football is not a new phenomenon. There have been periods where it seemed to have vanished, through efforts to prohibit racist behaviours from and amongst the supporters 
and governmental attempts to prevent racism through legislation. However, recent episodes in major leagues across Europe suggest that it persists.

The objective of this paper has been to develop a causal loop diagram that would capture the relevant aspects of racism in football through a holistic, top-down approach. To do so, a series of workshops/sessions has been organised with experts in the field and with the purpose of designing a tool that could be used to get better insights into how racism in football emerges and where the potential areas are where policymakers could use as leverage for effective counter-measures.

The main product of these sessions was as mentioned a Causal Loop Diagram, from which interesting results emerged. Firstly, different societal, political and economic aspects could act on and affect racism in football. As a result, it was confirmed that fighting racism in football could not succeed solely with anti-racism campaigns focusing on supporters' and players' behaviour. Second, the power structures of society and football should embrace the multicultural character of modern society if they are truly interested in fighting racism. Moreover, the judicial system of football should adapt to act more quickly when there is the suspicion that racism in football is on the rise. Finally, the authorities should engage the media in their effort to combat racism, since their widespread reach could facilitate the dissemination of ideas of equality.

The Causal Loop Diagram that was presented is not without limitations: it is only the first step in the route to better understand racism and its effect on football. Future avenues of research include the development of anti-racism initiatives based on the ideas generated by the diagram. Furthermore, the added value could be gained by developing a quantitative version of the CLD. Thus, communication to policymakers could be enhanced by showing numeric results of the consequences of anti-racism measures. Finally, greater insights could be gained if the sessions continue with people from different social strata; by expanding the inclusion of people, different perceptions could emerge and different approaches on how to combat racism.

\section{Acknowledgements}

The BRISWA project is co-funded by the Erasmus+ Sport Programme (Project Reference No: 579960-EPP-1-2016-2-IT-SPO-SCP). Furthermore, apart from the experts that participated in the Group Model Building Session, other people were involved in the development of the model: Dr Habib Sedehi, Prof. Edoardo Mollona and Dr Daniela Dasheva. We would like to express our gratitude to all of them for their contributions.

\section{Keywords}

systems thinking; racism; football; group model building; causal loop diagrams; complex systems; social dynamics; e+ sport

\section{Reference list}

Armenia, S., Tsaples, G., and Carlini, C. (2018), "Critical Events and Critical Infrastructures: A System Dynamics Approach”, in F. Dargam, P. Delias, I. Linden and B. Mareschal (eds), 
Decision Support Systems VIII: Sustainable Data-Driven and Evidence-Based Decision Support. Proceedings of the $4^{\text {th }}$ International Conference, ICDSST 2018, Heraklion, Greece, May 22-25, 2018, pp. 55-66, Cham (Switzerland): Springer.

Bains, J., and Johal, S. (1998), Corner Flags and Corner Shops: The Asian Football Experience, London: Phoenix.

Bradbury, S. (2013), "Institutional Racism, Whiteness and the Under-Representation of Minorities in Leadership Positions in Football in Europe", Soccer \& Society, 14 (3): 296314.

Burdsey, D. (2006), "No Ball Games Allowed? a Socio-Historical Examination of the Development and Social Significance of British Asian Football Clubs", Journal of Ethnic Migration Studies, 32 (3): 477-496.

Burdsey, D. (2007), British Asians and Football: Culture, Identity and Exclusion, London: Routledge.

Burdsey, D. (2014), “One Week in October: Luis Suarez, John Terry and the Turn to Racial Neoliberalism in English Men's Professional Football”, Identities: Global Studies in Culture and Power, 21 (5): 429-447.

Cashmore, E., and Cleland, J. (2014), Football's Dark Side: Corruption, Homophobia, Violence and Racism in the Beautiful Game, London/New York: Palgrave Macmillan.

Doidge, M. (2015), “'If You Jump up and down Balotelli Dies': Racism and Player Abuse in Italian Football", Internation Review for the Sociology of Sport, 50 (3): 249-269.

FIFA (2006), Fair-Play. Available online at http://www.fifa.com/sustainability/fair-play.html (last accessed: April 15, 2017).

Garland, J., and Rowe, M. (1999), "Selling the Game Short: An Examination of the Role of Antiracism in British Football", Sociology of Sport Journal, 16 (1): 33-53.

Garland, J., and Rowe, M. (2001), Racism and Anti-Racism in Football, Basingstoke: Palgrave.

Kassimeris, C. (2009), Anti-Racism in European Football: Fairplay for All, Plymouth: Lexington Press.

King, C. (2004), Offside Racism, Oxford: Berg.

Krasnoff, L.S. (2017), "Devolution of Les Bleus as a Symbol of a Multicultural French Future", Soccer $\mathcal{E}$ Society, 18 (2-3): 311-319.

Llopis-Goig, R. (2013), “Racism, Xenophobia and Intolerance in Spanish Football: Evolution and Responses from the Government and the Civil Society", Soccer E Society, 14 (2): 262276.

Long, J. (2000), “No Racism Here? a Preliminary Examination of Sporting Innocence", Managing Leisure, 5: 121-133.

Long, J., Hylton, K., Welch, M., and Dart, J. (2000), Part of the Game? An Examination of Racism in Grassroots football, Leeds: Leeds Metropolitan University, School of Leisure and Sports Studies, Kick it Out/Centre for Leisure and Sport Research.

Long, J., Hylton, K., Sprancklen, A., Ratna, A., and Bailey, S. (2009), Systematic Review of the Literature on Black and Minority Ethnic Communities in Sport and Physical Recreation, Leeds: Carnegie Research University. 
Macpherson, W. (1999), The Stephen Lawrence Inquiry: Report of an Inquiry by Sir William Macpherson of Cluny, London: Stationary Office.

Meadows, D. (1980), "The Unavoidable A Priori", in J. Randers (ed.), Elements of the System Dynamics Method, pp. 23-57, Cambridge (MA): MIT Press.

Müller, Floris, van Zoonen, L., and de Roode, L. (2007), “Accidental Racists: Experiences and Contradictions of Racism in Local Amsterdam Soccer Fan Culture", Soccer E Society, 8 (2-3): 335-350.

Myrovali, G., Tsaples, G., Morfoulaki, M., Aifadopoulou, G., and Papathanasiou, J. (2018), “An Interactive Learning Environment Based on System Dynamics Methodology for Sustainable Mobility Challenges Communication \& Citizens' Engagement", Lecture Notes in Business Information Processing, 313: 88-99.

Pinto, T., Drew, D., and Minhas, N. (1997), Sheffield Divided or United? A Study of "Race" and Football, Sheffield: Sheffield Hallam University.

Renfrew, D., and Snyder, G. M. (2016), “'When Said with a Sneer': Translating Language, Race and Culture through an English Football Race Controversy", City \& Society, 28 (3): 319340.

Solomos, J., and Back, L. (1996), Racism and Society, Basingstoke: Macmillan.

Sterman, J. (2000), Business Dynamics: Systems Thinking and Modeling for a Complex World, Boston (MA): Irwin/McGraw-Hill.

Talbot, D., and Bose, M. (2007), "Racism, Criminalization and the Development of Night-Time Economies: Two Case Studies in London and Manchester", Ethnic and Racial Studies, 30 (1): 95-118.

The Daily Telegraph (2012, September 27), “John Terry Racism Row with Anton Ferdinand: Timeline", The Daily Telegraph. Available online at http://www.telegraph.co.uk/sport/football/teams/chelsea/8860484/John-Terry-racismrow-with-Anton-Ferdinand-timeline.html (last accessed: April 15, 2017). 